\title{
What evidence exists on the impacts of chemicals arising from human activity on tropical reef-building corals? A systematic map protocol
}

\author{
Dakis-Yaoba Ouédraogo ${ }^{1^{*}}$ (D), Romain Sordello², Sophie Brugneaux ${ }^{3}$, Karen Burga $^{4}$, Christophe Calvayrac ${ }^{5,6}$, \\ Magalie Castelin, Isabelle Domart-Coulon ${ }^{8}$, Christine Ferrier-Pagès ${ }^{9}$, Mireille M. M. Guillaume ${ }^{10,11}$, \\ Laetitia Hédouin $^{11,12}$, Pascale Joannot ${ }^{13}$, Olivier Perceval ${ }^{14}$ and Yorick Reyjol ${ }^{2}$
}

\begin{abstract}
Background: Tropical coral reefs cover ca. $0.1 \%$ of the Earth's surface but host an outstanding biodiversity and provide important ecosystem services to millions of people living nearby. However, they are currently threatened by both local (e.g. nutrient enrichment and chemical pollution of coastal reefs, arising from poor land management, agriculture and industry) and global stressors (mainly seawater warming and acidification, i.e. climate change). Global and local stressors interact together in different ways, but the presence of one stressor often reduces the tolerance to additional stress. While global stressors cannot be halted by local actions, local stressors can be reduced through ecosystem management, therefore minimizing the impact of climate change on reefs. To inform decision-makers, we propose here to systematically map the evidence of impacts of chemicals arising from anthropogenic activities on tropical reef-building corals, which are the main engineer species of reef ecosystems. We aim to identify the combinations of chemical and coral responses that have attracted the most attention and for which evidence can be further summarized in a systematic review that will give practical information to decision-makers.

Methods: The systematic map will follow the Collaboration for Environmental Evidence Guidelines and Standards for Evidence Synthesis in Environmental Management. We will search the relevant literature using English terms combined in a tested search string in two publication databases (Web Of Science Core Collection and Scopus). The search string will combine terms describing the population (tropical reef-building corals) and the exposure (chemicals). We will supplement this literature with some more obtained through search engines, specialist websites, and through a call to local stakeholders. Titles, abstracts, and full-texts will then be successively screened using pre-defined eligibility criteria. A list of pre-defined variables will then be extracted from full-texts. Finally, a database of all studies included in the map with coded metadata will be produced. The evidence will be described in a map report with text, figures and tables, and a matrix showing the distribution and frequency of included study into types of exposure and types of outcomes will be computed to identify potential knowledge gaps and knowledge clusters.
\end{abstract}

Keywords: Contamination, Hermatypic, Nutrients, Pollution, Scleractinian

*Correspondence: dakis.ouedraogo@gmail.com; dakis-yaoba. ouedraogo@mnhn.fr

${ }^{1}$ Direction de l'Expertise, Muséum National d'Histoire Naturelle (MNHN), 75005 Paris, France

Full list of author information is available at the end of the article

\section{Background}

Tropical coral reefs cover ca. $0.1 \%$ of the Earth's surface but they host an outstanding biodiversity [1] and provide important ecosystem services to millions of people living

c) The Author(s) 2020. This article is licensed under a Creative Commons Attribution 4.0 International License, which permits use, sharing, adaptation, distribution and reproduction in any medium or format, as long as you give appropriate credit to the original author(s) and the source, provide a link to the Creative Commons licence, and indicate if changes were made. The images or other third party material in this article are included in the article's Creative Commons licence, unless indicated otherwise in a credit line to the material. If material is not included in the article's Creative Commons licence and your intended use is not permitted by statutory regulation or exceeds the permitted use, you will need to obtain permission directly from the copyright holder. To view a copy of this licence, visit http://creativeco mmons.org/licenses/by/4.0/. The Creative Commons Public Domain Dedication waiver (http://creativecommons.org/publicdomain/ zero/1.0/) applies to the data made available in this article, unless otherwise stated in a credit line to the data. 
nearby $[2,3]$. Despite their biological and economical importance, 75 percent of the world's tropical coral reefs are currently threatened by both local and global stressors $[2,4,5]$. The prominent global threats are represented by seawater warming and acidification [6], while local threats are mainly unsustainable and destructive development of coastal areas, excess sedimentation, overfishing, as well as nutrient and chemical pollution arising from poor land management, agriculture and industry $[7$, 8]. Global and local stressors interact together in different ways, but the presence of one stressor often reduces the physiological tolerance of individuals to additional stresses. For example, corals are hyper-sensitive to seawater warming if they are already physiologically stressed by poor water quality [9]. While global stressors cannot be halted by local actions, local stressors can be reduced through ecosystem management, therefore largely minimizing the climate change impacts on reefs [10].

The health of reef ecosystems is largely based on the health of their main engineer species, the reef building corals, which are not only responsible for reef accretion, but also make three-dimensional structures serving as habitat and food for other reef organisms. The vast majority of such corals (hermatypic corals, sensu [11]) are colonial scleractinian corals (Cnidaria Hexacorallia) living in association with endosymbiotic dinoflagellate algae belonging to the Symbiodiniaceae family [12]. Symbionts are key to the success of corals in oligotrophic reef waters as they transfer most of the photosyntheticallyacquired nutrients to the coral host for its own use [13, 14]. This association is however fragile. Many reviews have now made clear the fact that elevation in seawater temperature above a certain threshold is the main factor responsible for the breakdown of the coral-algal symbiosis also called coral bleaching (see for example [15]). As symbionts are the main nutritional source for corals, prolonged bleaching condition may ultimately lead to coral death, and reduced reef health. Coral symbiosis is also largely impacted in coastal reefs by water pollution, which is a major threat per se [16], but also reduces coral resistance to thermal stress and acidification [17, 18]. According to the type of pollution, the host, the symbionts or both partners can be impacted, through reduced calcification or photosynthesis, enhanced bleaching or cellular damage, and reduced fecundity among other damages [19-21]. The effect of water pollution on corals is a vast subject, due to the many possible pollutants, and interactions among pollutants or with other environmental stressors. While several reviews have focused on the subject (e.g. [22, 23]), they often tackled only one source of pollution or class of chemicals such as nutrients [24], herbicides [25], oil [26] or sunscreen ingredients [27]. Also, none of these reviews are systematic and have assessed the major form of pollutants in reef waters, or the major coral process(es) affected.

In this paper, we thus present a protocol to systematically map the evidence related to the impacts of chemicals arising from human activities on tropical reefbuilding corals. Such knowledge is essential for an effective ecosystem management and coral reef protection.

\section{Topic identification and stakeholder input}

In the French Overseas territories, coral reefs cover $14,280 \mathrm{~km}^{2}$ corresponding to $5 \%$ of world total coral reef area [28]. France is hence the 4th country with the largest coral reef area in the world after Indonesia (18\% of world total area), Australia (17\%) and the Philippines (9\%) [28], and therefore has substantial responsibility concerning coral reef protection. The French Ministry of Ecology has recently launched an assignment for a systematic review aiming to assess the impacts of chemicals and nutrients on coral reefs in order to gather and analyse the existing knowledge on this topic and find ways to improve coral reef protection and management at the national scale. The review team formulated the primary question of the review and its components, focusing on reef-building corals that are the main engineer species of reef ecosystems, and this was then approved by the French Ministry of Ecology. The French Ministry of Ecology, as well as the French Ministry for Overseas Territories are part of the steering committee of the project, and will therefore regularly follow the progress of the review. Because the topic is very large (all chemicals and all types of coral response should be considered) the first step of this assignment is to produce a systematic map of the evidence. We will thus be able to identify the combinations of chemicals and coral responses that have been the most documented and for which evidence can be further summarized in a systematic review.

\section{Objective of the review}

\section{Primary question}

The primary question of this systematic map is: What evidence exists on the impacts of chemicals arising from human activity on tropical reef-building corals?

\section{Components of the primary question}

The above primary question has the following key elements:

Population: All tropical reef-building coral species (hermatypic scleractinian species, Millepora sp., Heliopora sp. and Tubipora sp.).

Exposure: All natural, geogenic and synthetic chemicals coming from human activities. 
Comparator: Population not exposed to chemicals; Population prior to chemical exposure; Population exposed to a different concentration of chemicals.

Outcomes: All outcomes related to tropical reefbuilding corals, from molecular level (e.g. gene expression, enzyme activities) to community level (e.g. coral cover, species richness) (Fig. 1).

\section{Methods}

The systematic map will follow the Collaboration for Environmental Evidence Guidelines and Standards for Evidence Synthesis in Environmental Management [29] and it conforms to ROSES reporting standards [30] (see Additional file 1).

\section{Searching for articles Search terms and languages}

Searches will be performed using search terms exclusively in English language. The search with English search terms can however retrieve articles written in languages other than English, and articles written in English and French will be included (see section Eligibility criteria). The list of search terms is presented in the next section (see Search strings).

\section{Search string}

A scoping exercise in Web of Science Core Collection (WOS CC, see the institutional subscriptions used in section "Bibliographic databases") database was conducted to build the search string, using terms describing population and terms describing exposure (Additional file 2). To describe exposure, a detailed list of all the chemicals is impossible to establish because of their large numberfor example the European Inventory of existing commercial chemical substances (ENIECS) includes more than 100,000 chemicals [31]. We therefore adopted the following approach to capture all the chemicals that could have an impact on corals. We listed the terms according to four levels of increasing specificity: (i) generic terms (e.g. contamination, pollution, chemicals); (ii) pressures (e.g. sewage, runoff) and usages (e.g. consumer product, biocide); (iii) classes of chemicals (e.g. nutrient, metal, pesticide, cosmetic, detergent, microplastic, petroleum); and (iv) within some classes of chemicals (e.g. metal), specific chemicals identified based on expert knowledge and whose impacts have been particularly studied in tropical corals (e.g. nickel, copper). Finally, the best combination of search terms obtained (i.e. that gave the highest comprehensiveness and specificity) is described below (Web Of Science format):

$\mathrm{TS}=($ coral\$ AND (contamin* OR pollut* OR toxicant\$ OR chemical\$ OR "industrial discharge\$" OR runoff OR

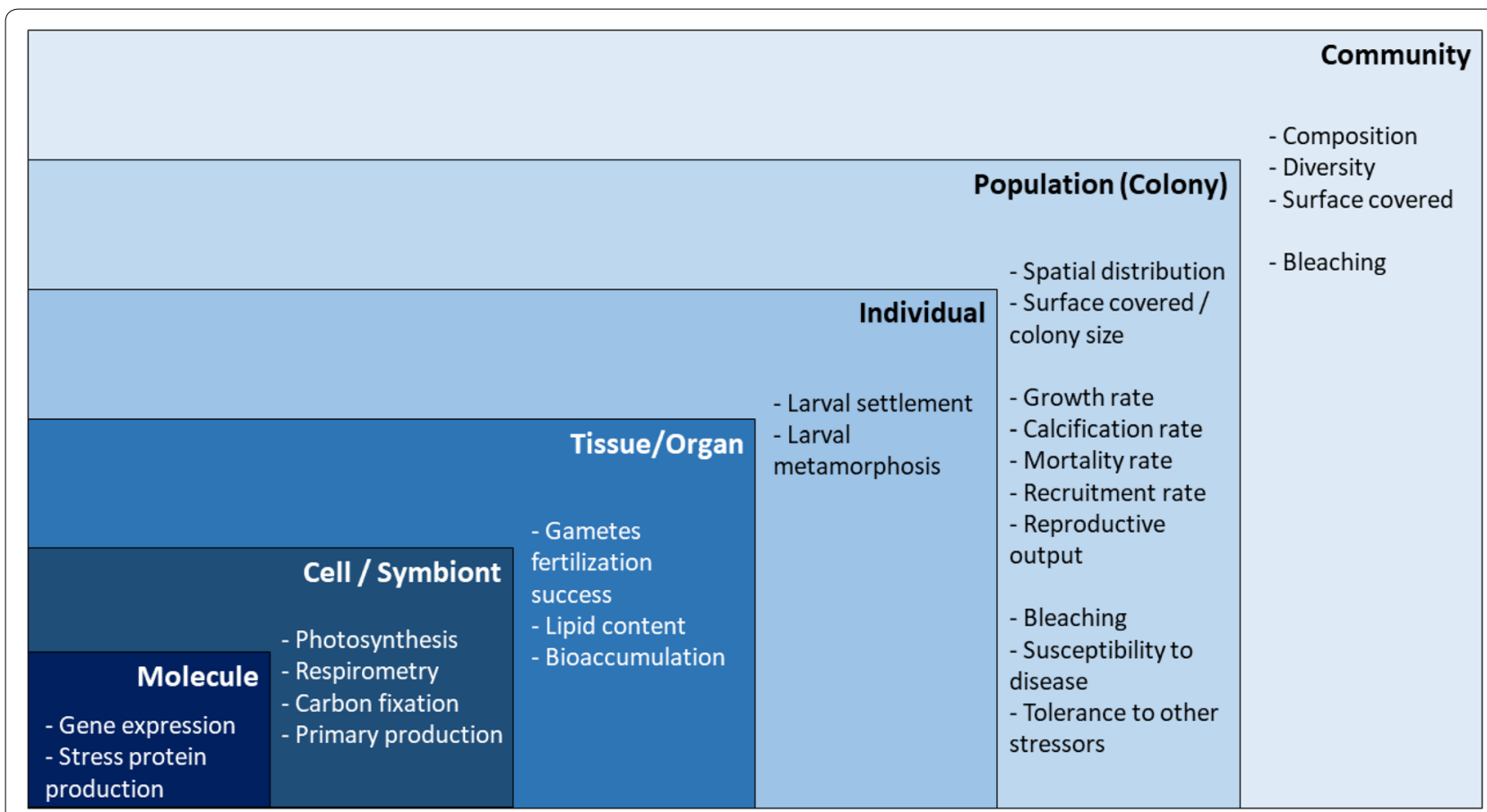

Fig. 1 Description of the outcomes of the primary question organized by biological levels. All outcomes related to tropical reef-building corals will be considered including but not restricted to those presented here 
run-off OR sewage OR eutrophication OR effluent\$ OR waste\$water OR waste-water OR "shipping" OR biocide\$ OR "industrial product\$” OR "consumer product\$” OR "household product\$" OR "biocidal product\$" OR disinfect* OR nutrient\$ OR oil OR metal\$ OR pesticide\$ OR herbicide\$ OR insecticide\$ OR fungicide\$ OR antifoul* OR anti-foul* OR organochlorine\$ OR "flame retardant\$" OR detergent\$ OR "perfluorinated compound\$” OR pharmaceutical\$ OR "personal care product\$" OR cosmetic\$ OR PAH\$ OR petroleum OR hydrocarbon\$ OR microplastic\$ OR nanoparticle\$ OR nano-particle\$ OR "endocrine disrupt" dispersant\$ OR metalloid\$ OR solvent\$ OR petrochemical\$ OR additive\$ OR preservative\$ OR plasticizer\$ OR hormone\$ OR "transformation product\$" OR "degradation product\$" OR byproduct\$ OR by-product\$ OR sunscreen\$ OR "UV filter\$" OR "ultraviolet filter\$" OR antibiotic\$ OR phthalate\$ OR PCB\$ OR cyanide\$ OR chlordecone OR nickel OR copper OR zinc OR cadmium OR mercury OR iron)).

\section{Estimating the comprehensiveness of the search}

To assess the comprehensiveness of the search string, we used a test list of 58 articles considered by the review team as relevant to answer our question and spanning a wide range of chemicals (Additional file 3).

\section{Bibliographic databases}

Given the number of articles retrieved by our search string during the scoping exercise and the resources available to conduct the systematic map, we will perform searches on two online publication databases. We selected two multidisciplinary databases Scopus (Elsevier) and WOS CC (Clarivate Analytics) that we can access through a CNRS (the French National Centre for Scientific Research) subscription. Scopus is the largest citation database of peer-reviewed literature and WOS $\mathrm{CC}$ is the world's original citation index for scientific and scholarly research. Both databases are well-suited for use as principal search system to evidence synthesis [32]. Among the 58 articles of our test list, 97\% (56/58) were indexed in Scopus and 97\% (56/58) in WOS CC (Additional file 3) indicating that both databases were highly relevant for our literature search. We will adapt the abovementioned search string to fit the search facilities of the Scopus database (Additional file 4).

We had access to the following WOS CC Citation Indexes: Science Citation Index Expanded (SCIEXPANDED, 1900-present), Social Sciences Citation Index (SSCI, 1956-present), Arts \& Humanities Citation Index (A\&HCI, 1975-present), Conference Proceedings Citation Index- Science (CPCI-S, 1998-present), Conference Proceedings Citation Index- Social Science
\& Humanities (CPCI-SSH, 1998-present), Emerging Sources Citation Index (ESCI, 2015-present); and Chemical Indexes: Current Chemical Reactions (CCREXPANDED, 1985-present, includes Institut National de la Propriete Industrielle structure data back to 1840), Index Chemicus (IC, 1993-present). We had access to all Scopus database (1788-present). No time restriction will be applied during searches.

Details on number of search hits returned by the search string on the two databases are provided in additional file 2 .

\section{Internet searches}

Additional searches of literature will be performed using three search engines:

- CORE (https://core.ac.uk/)

- Google Scholar (https://scholar.google.fr/)

- GreenFILE (http://www.greeninfoonline.com).

The search string developed during the scoping exercise on WOS CC database will be adapted to fit the search facilities of these search engines (for instance Google Scholar allows limited Boolean operators and search string is limited to 256 characters ([33], Additional file 4). Searches will be performed on titles, then the results will be sorted by relevance and the first 400 hits will be extracted. Extraction of results from CORE will be done one by one into Zotero using the Zotero connector for web browser. Results from Google Scholar will be extracted using the software Publish or Perish version 7.15.2643.7260 (https://harzing.com/resources/publishor-perish, accessed 16 March 2020). Results from GreenFile will be extracted using the offered export facilities (results can be sent by email in various bibliographic formats e.g. RIS format).

Additionally, we will also search for dissertations in ProQuest Dissertations and Theses (https://search.proqu est.com/, Publicly Available Content Database), Open Access Theses and Dissertations (https://oatd.org/) and the French thesis repository (https://www.theses.fr/). The search string will be adapted to fit the specificities of each repository. Searches will be performed on titles, then the results will be sorted by relevance and the first 100 hits will be extracted.

\section{Specialist searches}

We will search for links or references to relevant articles and data on the following 11 specialist websites (Englishor French-written websites):

- Australian Institute of Marine Science (https://www. aims.gov.au/) 
- Coral Health and Monitoring Program (NOAA, (https://www.coral.noaa.gov/)

- Coral traits database (https://coraltraits.org/)

- Ecotox knowledge base of the United States Environmental Protection Agency (EPA, https://cfpub.epa. gov/ecotox/)

- French Coral Reef Initiative (IFRECOR, https://ifrec or.fr)

- French Research Institute for Exploitation of the Sea (IFREMER, https://wwz.ifremer.fr/)

- International Coral Reef Initiative (ICRI, https:// www.icriforum.org/)

- International Coral Reef Society (ICRS, http://coral reefs.org/)

- LabEx CORAIL (https://www.labex-corail.fr/)

- ReefBase-A global information system for coral reefs (http://www.reefbase.org/)

- The Endocrine Disruption Exchange (TEDX) List of Potential Endocrine Disruptors (https://endocrined isruption.org/interactive-tools/tedx-list-of-potentialendocrine-disruptors).

\section{Call for literature}

A call for literature will be addressed to the French overseas local authorities. In particular, the local French Coral Reef Initiative (IFRECOR) committees will be contacted.

\section{Assembling and managing search results}

The results of all searches will be collated and duplicates will be removed using the package revtools in the $\mathrm{R}$ software [34]. The map will be managed with the $\mathrm{R}$ and Microsoft Excel softwares, and reference management softwares (EndNote and Zotero) will be specifically used for searching for full-texts.

\section{Article screening and study eligibility criteria Screening process}

Articles will be screened for eligibility in two successive stages: first on titles and abstracts, and second on fulltexts. Articles with unclear eligibility status during title/ abstract screening will be included for full text screening. The list of articles with unclear eligibility status after completion of full-text screening will be provided with explanation of why they could not be classified. Articles without an abstract and retained based on title screening will directly be screened on their full-text.

Screening will be performed by at least two reviewers. Before screening, we will assess the consistency between reviewers' decisions by computing the Randolph's Kappa coefficient on a number of references randomly sampled among the set of articles. We will randomly sample $10 \%$ of articles for screening on titles and abstracts, and
$5 \%$ for screening on full-texts. We will consider a minimal coefficient of 0.6 as an acceptable level of agreement between reviewers, and the process will be repeated until reaching this level. All disagreements between reviewers will be discussed whatever the value of the coefficient, and the definition of eligibility criteria will be improved where necessary.

During all screening process, we will ensure that reviewers will never have to screen their own articles.

\section{Eligibility criteria}

At each stage, the eligibility of articles will be assessed using the criteria displayed in Table 1.

The list of articles rejected at full-text screening will be provided with their reasons for exclusion. Reviews and meta-analyses will be excluded but those eligible according to the Population-Exposure-Outcome criteria will be listed in a separate file to make them easily accessible for possible further use.

\section{Study validity assessment}

No critical appraisal of study will be performed for the systematic map.

\section{Data coding strategy}

A list of variables will be recorded in Microsoft Excel sheet from full-texts for all studies included in the map (full details are given in Additional file 5):

- Bibliographic information (unique identifier, source, title, authors, journal, year, DOI, language and publication type)

- General description of the study (publication content, country, latitude and longitude or location)

- Description of the population (taxon and taxon level)

- Description of the exposure (as described by the authors and as defined by the review team)

- Description of the type of outcome(s) (as described by the authors and as defined by the review team)

Data coding will be performed using an a priori specified CodeBook (Additional file 5) by at least two reviewers. Before the actual coding, a random selection of $1 \%$ of articles with a minimum of ten articles will be independently coded by the reviewers and potential disagreements will be discussed and solved, and the CodeBook will be improved where necessary. In case of missing or unclear information, it will be coded as such.

\section{Study mapping and presentation}

We will produce a database (Microsoft Excel sheet) of all included studies and their coded data. This database will be open access and included as an appendix 
Table 1 Eligibility criteria

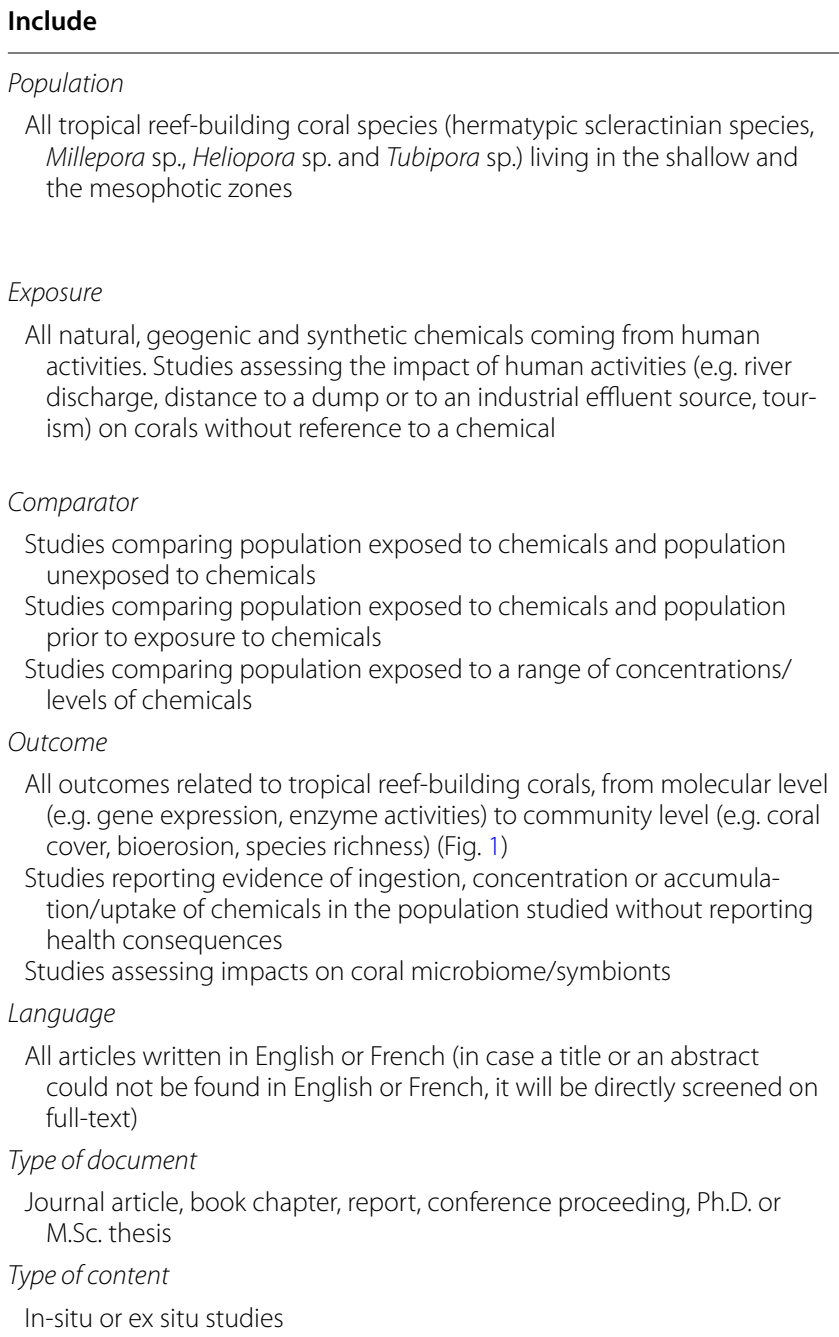

All tropical reef-building coral species (hermatypic scleractinian species, Millepora sp., Heliopora sp. and Tubipora sp.) living in the shallow and the mesophotic zones

Exposure

All natural, geogenic and synthetic chemicals coming from human activities. Studies assessing the impact of human activities (e.g. river discharge, distance to a dump or to an industrial effluent source, tourism) on corals without reference to a chemical

\section{Exclude}

Cold-water or deep-water corals

Ahermatypic corals

Free-living zooxanthellae (not as symbionts in corals)

Studies conducted in coral reefs but not about corals (e.g. about coral reef fishes)

Studies assessing the impact of chemicals coming from natural sources (e.g. nutrients from guano)

Studies assessing the impact of sedimentation per se or of physical disturbances on coral

Marine debris, macro-plastics
Presentation, editorial material, letter or news item, conference or meeting abstract, poster

Reviews and meta-analyses, modelling studies without experimental data to the systematic map publication. In the map report, a narrative synthesis approach with descriptive statistics, tables and figures will be used to describe the geographical distribution of the included studies as well as their frequencies in the categories specified in the CodeBook. A matrix showing the distribution and frequency of included study into types of exposure and types of outcomes will be computed. The types of exposure and outcomes a priori defined in the CodeBook will be used, but we may also use de novo types that may emerge during the meta-coding process. The matrix will be plotted as a heat map to visually identify potential knowledge gaps and knowledge clusters. We will thus identify the clusters(s) for which a full synthesis of evidence (systematic review) should be possible.

\section{Supplementary information}

Supplementary information accompanies this paper at https://doi. org/10.1186/s13750-020-00203-x.

Additional file 1. ROSES systematic map protocols checklist. ROSES form for systematic map protocols version 1.0.

Additional file 2. Search string development. Details of the scoping exercise performed to build the search string.

Additional file 3. Test list. List of the 58 articles used to assess the comprehensiveness of the search string.

Additional file 4. Search strings. Search strings that will be used for searching in publication databases and search engines.

Additional file 5. Coding book. Description of the data that will be extracted for the systematic map. 


\section{Acknowledgements}

The authors thank Pierre Lecoq, Christophe Rousselle and Bernard Salvat for providing relevant articles to assess the comprehensiveness of our search string.

\section{Authors' contributions}

The first scoping exercise to build the search string was performed by RS, OP, YR, SB and DYO. Then DYO refined it and all authors discussed and approved the final search string. DYO produced a first draft of the manuscript that was revised by RS and YR. All authors read and approved the final manuscript.

\section{Funding}

This map was funded by the French Office for Biodiversity (OFB) and the French National Museum of Natural History (MNHN).

\section{Availability of data and materials}

All data generated or analysed during this study are included in this published article and its supplementary information files.

\section{Ethics approval and consent to participate}

Not applicable.

\section{Consent for publication}

Not applicable.

\section{Competing interests}

In 2018, CFP collaborated with the private company "L'Oréal"for a research work on the impact of sunscreen ingredients on a coral species. LH is currently conducting research on the effects of cosmetic ingredients on young stages of corals of French Polynesia for the private company "Comptoir du Monoi".

\section{Author details}

${ }^{1}$ Direction de l'Expertise, Muséum National d'Histoire Naturelle (MNHN), 75005 Paris, France. ${ }^{2}$ UMS PatriNat, OFB - MNHN - CNRS, 75005 Paris, France. ${ }^{3}$ Direction des Outres mers, Office Français Pour la Biodiversité (OFB), 29200 Brest, France. ${ }^{4}$ French Agency for Food, Environmental and Occupational Health \& Safety (ANSES), 94701 Maisons-Alfort Cedex, France. ${ }^{5}$ Biocapteurs Analyses Environnement, University of Perpignan via Domitia, 66000 Perpignan, France. ${ }^{6}$ Laboratoire de Biodiversité et Biotechnologies Microbiennes (LBBM), Sorbonne Universités - CNRS, 66650 Banyuls Sur Mer, France. ${ }^{7}$ Institut de Systématique Evolution, Biodiversité (ISYEB), Muséum National d'Histoire Naturelle - CNRS - Sorbonne Université - EPHE - Université des Antilles, 75005 Paris, France. ${ }^{8}$ Laboratoire Molécules de Communication et Adaptation des Microorganismes (MCAM), UMR 7245, CNRS - Muséum National d'Histoire Naturelle (MNHN), 75005 Paris, France. ${ }^{9}$ Equipe Ecophysiologie Corallienne, Centre Scientifique de Monaco, 98000 Monaco, Monaco. ${ }^{10}$ Laboratoire de Biologie des Organismes et Ecosystèmes Aquatiques (BOrEA), Muséum National d'Histoire Naturelle - CNRS - SU - IRD - UCN - UA EcoFunc - Aviv, 75005 Paris, France. ${ }^{11}$ Laboratoire d'Excellence CORAIL, 66860 Perpignan, France. ${ }^{12}$ USR 3278 CRIOBE, PSL Université Paris : EPHE - UPVD - CNRS, 98729 Papetoai, Mo'orea, French Polynesia. ${ }^{13}$ Direction du Pôle Expéditions - DGD C, Muséum National d'Histoire Naturelle (MNHN), 75005 Paris, France. ${ }^{14}$ Office Français de la Biodiversité (OFB), 94300 Vincennes, France.

\section{Received: 3 April 2020 Accepted: 26 August 2020}

Published online: 03 September 2020

\section{References}

1. Hoeksema BW. The hidden biodiversity of tropical coral reefs. Biodiversity. 2017;18:8-12

2. Burke L, Reytar K, Spalding M, Perry A. Reefs at risk revisited. Washington DC: World Resources Institute; 2011.

3. Ferrario F, Beck MW, Storlazzi CD, Micheli F, Shepard CC, Airoldi L. The effectiveness of coral reefs for coastal hazard risk reduction and adaptation. Nat Commun. 2014;5:1-9.

4. Barlow J, França F, Gardner TA, Hicks CC, Lennox GD, Berenguer E, et al. The future of hyperdiverse tropical ecosystems. Nature. 2018;559:517-26.

5. Ellis J, Jamil T, Anlauf H, Coker DJ, Curdia J, Hewitt J, et al. Multiple stressor effects on coral reef ecosystems. Glob Change Biol. 2019;25:4131-46.
6. Hoegh-Guldberg O, Poloczanska ES, Skirving W, Dove S. Coral reef ecosystems under climate change and ocean acidification. Front Mar Sci. 2017;4:12.

7. Hoegh-Guldberg O, Pendleton L, Kaup A. People and the changing nature of coral reefs. Reg Stud Mar Sci. 2019;30:100699.

8. Wilkinson C. Status of coral reefs of the world: 2008. Global Coral Reef Monitoring Network and Reef and Rainforest Research Centre. Townsville, Australia; 2008.

9. Donovan MK, Adam TC, Shantz AA, Speare KE, Munsterman KS, Rice $\mathrm{MM}$, et al. Nitrogen pollution interacts with heat stress to increase coral bleaching across the seascape. Proc Natl Acad Sci. 2020;117:5351-7.

10. MacNeil MA, Mellin C, Matthews S, Wolff NH, McClanahan TR, Devlin M, et al. Water quality mediates resilience on the Great Barrier Reef. Nat Ecol Evol. Nature Publishing Group. 2019;3:620-7.

11. Schuhmacher $\mathrm{H}$, Zibrowius H. What is hermatypic? Coral Reefs. 1985:4:1-9.

12. LaJeunesse TC, Parkinson JE, Gabrielson PW, Jeong HJ, Reimer JD, Voolstra $\mathrm{CR}$, et al. Systematic revision of symbiodiniaceae highlights the antiquity and diversity of coral endosymbionts. Curr Biol. 2018;28(2570-2580):e6.

13. Muscatine $L$. The role of symbiotic algae in carbon and energy flux in reef corals. In: Dubinsky Z, editor. Coral Reefs. Elsevier: Amsterdam; 1990. p. 75-87.

14. Tremblay P, Grover R, Maguer JF, Legendre L, Ferrier-Pages C. Autotrophic carbon budget in coral tissue: a new 13C-based model of photosynthate translocation. J Exp Biol. 2012;215:1384-93.

15. Wilkinson CR. Global and local threats to coral reef functioning and existence: review and predictions. Mar Freshw Res. 1999;50:867-78.

16. Duprey NN, Yasuhara M, Baker DM. Reefs of tomorrow: eutrophication reduces coral biodiversity in an urbanized seascape. Glob Change Biol. 2016;22:3550-65

17. DeCarlo TM, Cohen AL, Barkley HC, Cobban Q, Young C, Shamberger KE, et al. Coral macrobioerosion is accelerated by ocean acidification and nutrients. Geology. 2015:43:7-10.

18. Wooldridge SA. Water quality and coral bleaching thresholds: formalising the linkage for the inshore reefs of the Great Barrier Reef, Australia. Mar Pollut Bull. 2009:58:745-51.

19. De BarrosMarangoni LF, Marques JA, Duarte GAS, Pereira CM, Calderon EN, Castro CB, et al. Copper effects on biomarkers associated with photosynthesis, oxidative status and calcification in the Brazilian coral Mussismilia harttii (Scleractinia, Mussidae). Mar Environ Res. 2017;130:248-57.

20. Prouty NG, Cohen A, Yates KK, Storlazzi CD, Swarzenski PW, White D. Vulnerability of coral reefs to bioerosion from land-based sources of pollution. J Geophys Res Oceans. 2017;122:9319-31.

21. Richmond RH, Tisthammer KH, Spies NP. The effects of anthropogenic stressors on reproduction and recruitment of corals and reef organisms. Front Mar Sci. 2018:5:12398.

22. Dubinsky ZVY, Stambler N. Marine pollution and coral reefs. Glob Change Biol. 1996;2:511-26

23. van Dam JW, Negri AP, Uthicke S, Mueller JF. Chapter 9: Chemical pollution on coral reefs: exposure and ecological effects. Ecol Impacts Toxic Chem. 2011. p. 187-211.

24. D'Angelo C, Wiedenmann J. Impacts of nutrient enrichment on coral reefs: new perspectives and implications for coastal management and reef survival. Curr Opin Environ Sustain. 2014;7:82-93.

25. Jones R. The ecotoxicological effects of Photosystem II herbicides on corals. Mar Pollut Bull. 2005;51:495-506.

26. Haapkyla J, Ramade F, Salvat B. Oil pollution on coral reefs: a review of the state of knowledge and management needs. Vie Milieu-Life Environ. 2007:57:95-111.

27. Wood E. Impacts of sunscreens on coral reefs. International Coral Reef Initiative (ICRI); 2018. p. 20.

28. Sheppard C, Davy S, Pilling G, Graham N. Coral reefs: biodiverse and productive tropical ecosystems. Oxford: Oxford University Press; 2018.

29. Collaboration for Environmental Evidence. Guidelines and Standards for Evidence synthesis in Environmental Management. Version 5.0 (AS Pullin, GK Frampton, B Livoreil \& G Petrokofsky, Eds) http://www.environmen talevidence.org/information-for-authors. Accessed 12 Nov 2019 [Internet]. Pullin A, Frampton G, Livoreil B, Petrokofsky G, editors. 2018 [cited 2019 Nov 12]. Available from: http://www.environmentalevidence.org/ information-for-authors. 
30. Haddaway N, Macura B, Whaley P, Pullin A. ROSES for Systematic Map Protocols Version 1.0. 2017. https://www.roses-reporting.com/systematic -map-protocols. Accessed 17 Feb 2020.

31. Geiss F, Bino GD, Blech G, Norager O, Orthmann E, Mosselmans G, et al. The EINECS inventory of existing chemical substances on the EC market. Toxicol Environ Chem. 1992;37:21-33.

32. Gusenbauer M, Haddaway NR. Which Academic Search Systems are Suitable for Systematic Reviews or Meta-Analyses? Evaluating Retrieval Qualities of Google Scholar, PubMed and 26 other Resources. Res Synth Methods. 2019;n/a.
33. Haddaway NR, Collins AM, Coughlin D, Kirk S. The Role of Google Scholar in evidence reviews and its applicability to grey literature searching. PLoS ONE. 2015;10:98.

34. Westgate MJ. revtools: an R package to support article screening for evidence synthesis. Res Synth Methods. 2019;10:606-14.

\section{Publisher's Note}

Springer Nature remains neutral with regard to jurisdictional claims in published maps and institutional affiliations.
Ready to submit your research? Choose BMC and benefit from:

- fast, convenient online submission

- thorough peer review by experienced researchers in your field

- rapid publication on acceptance

- support for research data, including large and complex data types

- gold Open Access which fosters wider collaboration and increased citations

- maximum visibility for your research: over $100 \mathrm{M}$ website views per year

At BMC, research is always in progress.

Learn more biomedcentral.com/submissions 